\title{
Design \& Analysis of Shell \& Tube Type Heat Exchanger
}

\author{
Arjun Kumar Prasad, Mr. Kaushik Anand \\ Department of Mechanical Engineering \\ K. .K. College of Engineering \& Management (KKCEM) \\ Berauti, Nepure, Deep Nagar (Biharsharif), Nalanda, Bihar - 803115 \\ March, 2019
}

\begin{abstract}
Shell and Tube heat exchangers are having special importance in boilers, oil coolers, condensers, pre-heaters. They are also widely used in process applications as well as the refrigeration and air conditioning industry. The robustness and medium weighted shape of Shell and Tube heat exchangers make them well suited for high pressure operations. The basic configuration of shell and tube heat exchangers, the thermal analysis and design of such exchangers form an included part of the mechanical, thermal, chemical engineering scholars for their curriculum and research activity.

This report presents the application of Differential Evolution (DE) for the optimal design of shell-and-tube heat exchangers. The main objective in any heat exchanger design is the estimation of the minimum heat transfer area required for a given heat duty, as it governs the overall cost of the heat exchanger. Many configurations are possible with various design variables such as outer diameter, pitch, and length of the tubes; tube passes; baffle spacing; baffle cut etc. Hence the design engineer needs an efficient strategy in searching for the global minimum.
\end{abstract}

\section{INTRODUCTION}

Heat exchangers are used to transfer thermal energy between two or more media and widely applicable to chemical industries, food industries, power engineering and so on. The shell

and tube heat exchanger is the most common heat exchanger type; therefore the study of its design and analysis is of great importance for conserving energy in heat exchange process.

Shell and Tube heat exchangers are having special importance in boilers ,oil coolers, condensers, pre-heaters . They are also widely used in process applications as well as the refrigeration and air conditioning industry. The robustness and medium weighted shape of Shell and Tube heat exchangers make them well suited for high pressure operations. The basic configuration of shell and tube heat exchangers, the thermal analysis and design of such exchangers form an included part of the mechanical, thermal ,chemical engineering scholars for their curriculum and research activity.

Shell and tube heat exchangers are used extensively throughout the process industry and

such a basic understanding $f$ their design, construction and performance is important to the practicing engineer.

The optimum thermal design of a shell and tube heat exchanger involves the consideration of many interacting design parameters which can be summarized as follows:

\subsection{PROCESS}

Process fluid assignments to shell side or tube side

Selection of stream temperature specifications.

Setting shell side and tube side pressure drop design limits.

Setting shell side and tube side velocity limits.

Selection of heat transfer models and fouling coefficients for shell side and tube side.

Selection of heat exchanger TEMA layout and number of passes.

Specification of tube parameters - size, layout, pitch and material.

Setting upper and lower design limits on tube length.

Specification of shell side parameters - materials, baffle cut, baffle spacing

One of the important processes in engineering is the heat exchange between flowing fluids, and many types of heat exchangers are employed in various types of installations, as petrol-chemical plants, process industries, pressurized water reactor power plants, nuclear power stations, building heating, ventilating, and air-conditioning and refrigeration systems. As far as construction design is concerned, the tubular or shell and tube type heat exchangers are widely in use.

The shell-and-tube heat exchangers are still the most common type in use. They have larger heat transfer surface area-tovolume ratios than the most of common types of heat exchangers, and they are manufactured easily for a large variety of sizes and flow configurations. They can operate at high pressures, and their construction facilitates disassembly for periodic maintenance and cleaning. The shell-and-tube heat exchangers consist of a bundle of tubes enclosed within a cylindrical 
shell. One fluid flows through the tubes and a second fluid flows within the space between the tubes and the shell. Typical Shell-and-Tube heat exchanger is shown in Figure 1.1

Heat exchangers in general and tubular heat exchangers in particular undergo deterioration in performance due to flow maldistribution. The common idealization in the basic tubular heat exchanger design theory is that the fluid is distributed uniformly at the inlet of the exchanger on each fluid side throughout the core. However, in practice, flow mal-distribution is more common and significantly reduces the idealized heat exchanger performance.

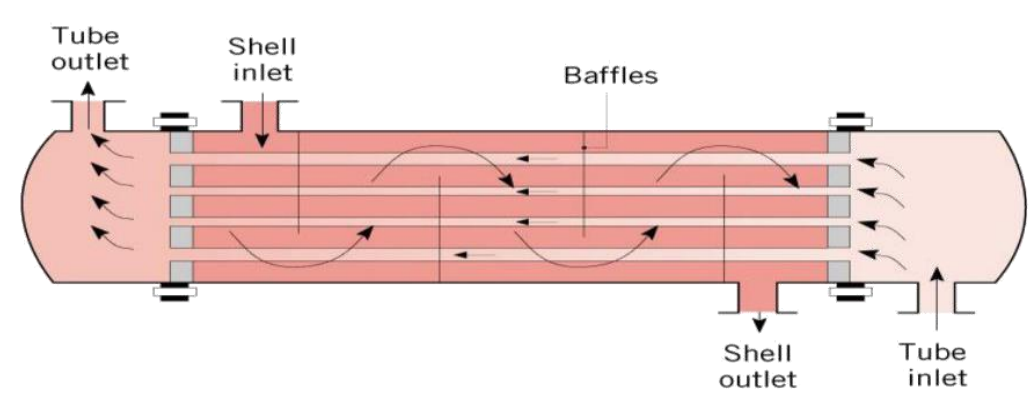

One Shell Pass and One Tube Pass Fig.1-One Shell and One Tube Pass Heat Exchanger

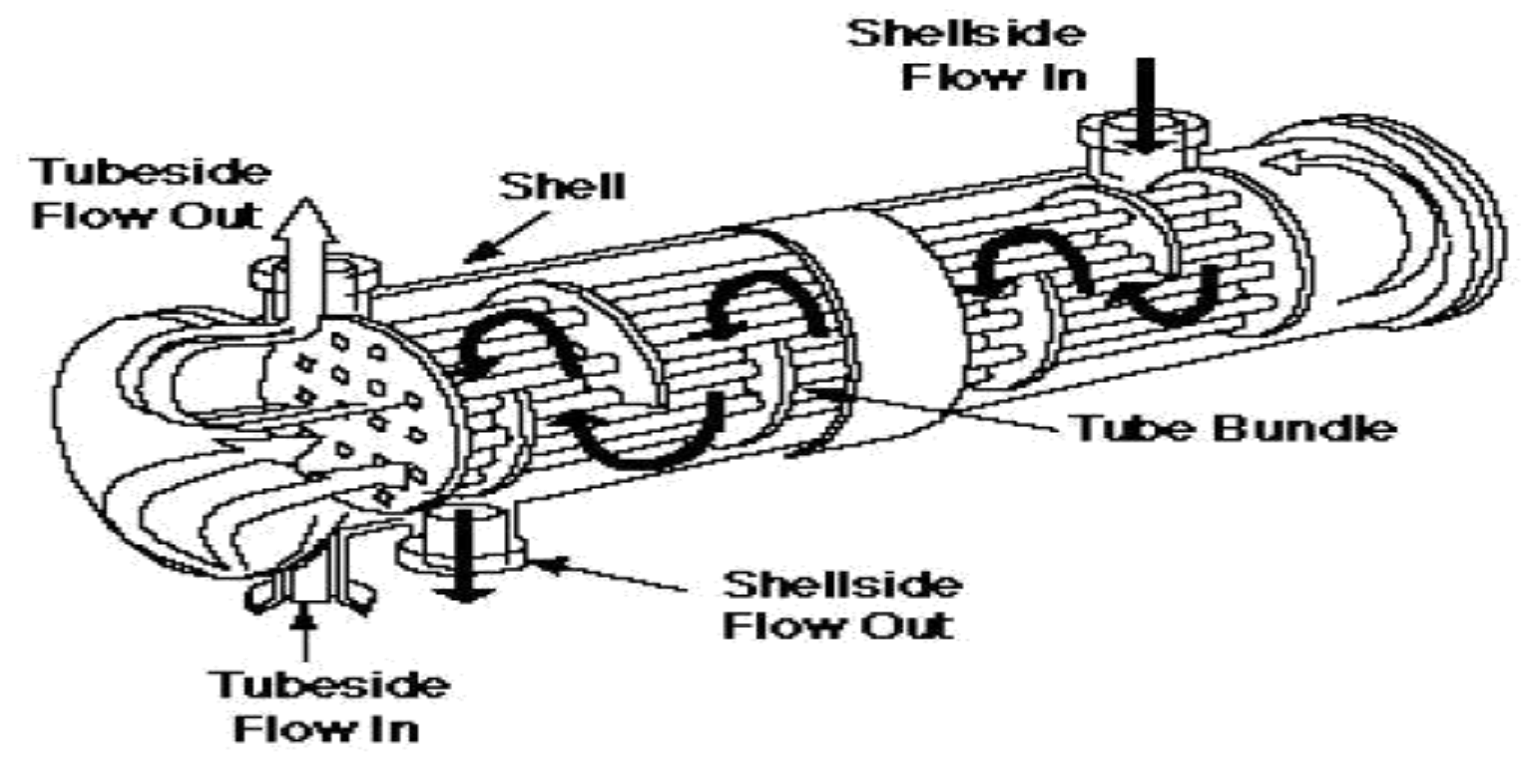

Fig.2-shell and tube heat exchanger

\section{PROBLEM SUMMARY}

- Inlet raw water temperature $=20^{\circ} \mathrm{C}$

- Inlet raw water pressure $=7.01 \mathrm{bar}$

- Mass flow rate of raw water $=150 \mathrm{~kg} / \mathrm{sec}$

- Inlet city water temperature from supply $=32^{\circ} \mathrm{C}$

- Inlet city water pressure $=5.75$ bar

- Mass flow rate of city water $=50 \mathrm{~kg} / \mathrm{sec}$

- Thermal conductivity of $0.5 \mathrm{Cr}$-alloy tube $=42.3 \mathrm{~W} / \mathrm{m}-\mathrm{K}$

- Outlet city water temperature $=25^{\circ} \mathrm{C}$

- The maximum flow velocity through the tube is also suggested to be $2 \mathrm{~m} / \mathrm{sec}$ to prevent erosion. 


\section{LITERATURE REVIEW}

WILFRIED ROETZEL, CHAKKRIT NA RANONG., [1] calculated the axial temperature profiles in a shell and tube heat exchanger by numerically for given maldistributions on the tube side. For comparison the same maldistributions are handled with the parabolic and hyperbolic dispersion model with fitted values for the axial dispersion coefficient and third sound wave velocity. The analytical results clearly demonstrate that the hyperbolic model is better suited to describe the steady state axial temperature profiles.

SAHOO, R.K., AND WILFRIED ROETZEL.,[2] derived The fundamental equations of hyperbolic model and its boundary conditions in terms of cross-sectional mean temperature from the basic equations of heat exchanger The traditional parabolic model and the proposed hyperbolic model which includes the parabolic model as a special case can be used for dispersive flux formulation. Instead of using the heuristic approach of parabolic or hyperbolic formulation, these models can be quantitatively derived from the axial temperature profiles of heat exchangers. In that paper both the models are derived for a shell-and-tube heat exchanger with pure maldistribution (without back mixing) in tube side flow and the plug flow on the shell side. The Mach number and the boundary condition which plays a key role in the hyperbolic dispersion have been derived and compared with previous investigation. It is observed that the hyperbolic model is the best suited one as it compares well with the actual calculations. This establishes the hyperbolic model and its boundary conditions.

WILFRIED ROETZEL, AND CHAKKRIT NA RANONG.,[3] tested and compared the newer

hyperbolic dispersion model and parabolic model considering the processes with pure maldistribution (without back mixing) on the tube side of a shell and tube heat exchanger and plug flow on shell side. The boundary conditions of the model equations are discussed in detail for the steady state and equations of the axial temperature profiles are provided in the programmable form. For the hyperbolic model simple relationships between the model parameters are derived. Considering the transient adiabatic processes in the tube bundle a concept for the experimental determination of the model parameter M, the third sound Mach number, is developed. Authors concluded that for an overall consideration of a heat exchanger with maldistribution the parabolic model is satisfactory. The parameter Pepar depends on both NTUs of the heat exchanger which makes the model difficult to handle. The advantage of the parabolic model is that only the only one parameter is needed. The hyperbolic model is superior to the parabolic model because it predicts the axial temperature profiles correctly, especially temperature jumps and (positive) slopes.

YIMINXUAN, WILFRIEDROETZEL.,[4] Applied the dispersion model is to the description of the effects of shell and tube side flow maldistribution. By means of this model, an efficient and versatile method of predicting transient response of multi pass shell and tube heat exchangers is developed. The method allows for effect of maldistribution on transient process, influence of heat capacities of fluids and solid components, arbitrary inlet temperature variations and step disturbances of flow rates. General forms of initial conditions and two different flow arrangements are considered. A general form of the solution for steady-state and dynamic simulation is derived. Temperature profiles are determined with numerical inversion of the Laplace transform. Some examples are calculated and the effect of maldistribution is discussed. Flow maldistribution hinders transient responses to any inlet changes and

decreases thermal effectiveness of heat exchangers. Its effect becomes more remarkable with increasing NTC'. The Peclet number has been used to quantitatively describe this kind of effect. The calculation has shown that the dispersion model should be applied instead of the plug-flow model if $\mathrm{Pe}<55$.

\section{BASIC PRINCIPLES OF DESIGN}

First of course, the heat exchanger must meet the process requirements. That is, it must effect the desired change in thermal condition of the process stream within the allowable pressure drops, and it must continue to do this until the next scheduled shutdown of the plant for maintenance.

Second, the exchanger must withstand the service condition of the plant environment. This includes the mechanical stresses of installation, startup, shutdown, normal operation, emergencies, and maintenance, and the thermal stresses induced by the temperature differences. It must also resist corrosion by the process and service streams (as well as by the environment); this is usually mainly a matter of choice of materials of construction, but Mechanical design does have some effect. Desirably, the exchanger should also resist fouling, but there is not much the designer may do with confidence in this regard except keep the velocities as high as pressure.

Third, the exchanger must be maintainable, which usually implies choosing a configuration that permits cleaning-tube-side, as may be indicated -and replacement of tubes and any other components that may be especially vulnerable to corrosion, erosion, or vibration. This requirement may also place limitations on positioning the exchanger and in providing clear space around it. 
Fourth, the exchanger should cost as little as is consistent with the above requirement; in the present context, this refers to first cost or installed cost, since operating cost or cost of lost production due to exchanger unavailability have already been considered by implication in the earlier and more important criteria.

Finally, there may be limitations on exchanger diameter, length, weight and/or tube specification due to site requirements, lifting and servicing capabilities, or inventory consideration.

\section{GENERALIZED DESIGN PROCEDURE OF HEAT EXCHANGER}

Process conditions (stream compositions, flow rates, temperatures, pressures) must be specified.

Required physical properties over the temperature and pressure ranges of interest must be obtained.

The type of heat exchanger to be employed is chosen.

A preliminary estimate of the size of the exchanger is made, using a heat transfer coefficient appropriate to the fluids, the process, and the equipment.

A first design is chosen, complete in all details necessary to carry out the design calculations.

The design chosen is now evaluated or rated, as to its ability to meet the process specifications with respect to both heat duty and pressure drop.

Based on this result a new configuration is chosen if necessary and the above step is repeated.

If the first design was inadequate to meet the required heat load, it is usually necessary to increase the size of the exchanger, while still remaining within specified or feasible limits of pressure drop, tube length, shell diameter, etc. This will sometimes mean going to multiple exchanger configurations. If the first design more than meets heat load requirements or does not use all the allowable pressure drop, a less expensive exchanger can usually be designed to fulfill process requirements.

The final design should meet process requirements (within the allowable error limits) at lowest cost. The lowest cost should include operation and maintenance costs and credit for ability to meet long-term process changes as well as installed (capital) cost. Exchangers should not be selected entirely on a lowest first cost basis, which frequently results in future penalties.

\section{BASIC DESIGN PROCEDURE OF HEAT EXCHANGER}

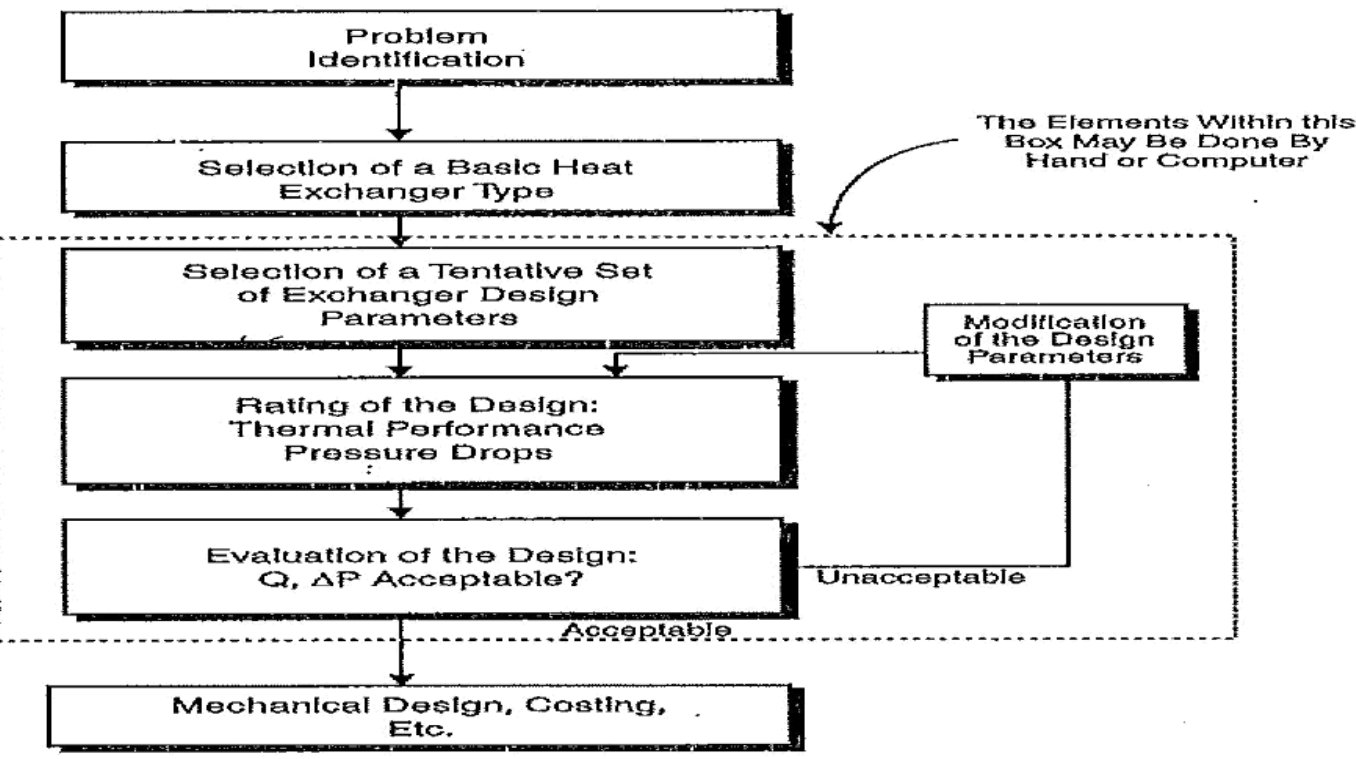

Fig.3-Basic Design Procedure of Heat Exchanger 


\section{7. $\quad$ COMPONENT OF SHELL AND TUBE HEAT EXCHANGER}

\subsection{WHY A SHELL AND TUBE HEAT EXCHANGER?}

Shell and tube heat exchangers in their various construction modifications are probably the most widespread and commonly used basic heat exchanger configuration in the process industries. The reasons for this general acceptance are several. The shell and tube heat exchanger provides a comparatively large ratio of heat transfer area to volume and weight. It provides this surface in a form which is relatively easy to construct in a wide range of sizes and which is mechanically rugged enough to withstand normal shop fabrication stresses, shipping and field erection stresses, and normal operating conditions. There are many modifications of the basic configuration, which can be used to solve special problems. The shell and tube exchanger can be reasonably easily cleaned, and those components most subject to failure - gaskets and tubes - can be easily replaced. Finally, good design methods exist, and the expertise and shop facilities for the successful design and construction of shell and tube exchangers are available throughout the world.

\subsection{BASIC COMPONENTS OF SHELL AND TUBE HEAT EXCHANGERS}

\subsubsection{TUBES:}

The tubes are the basic component of the shell and tube exchanger, providing the heat transfer surface between one fluid flowing inside the tube and the other fluid flowing across the outside of the tubes. The tubes may be seamless or welded and most commonly made of copper or steel alloys. Other alloys of nickel, titanium, or aluminum may also be required for specific applications.

\subsubsection{TUBE SHEETS:}

The tubes are held in place by being inserted into holes in the tube sheet and there either expanded into grooves cut into the holes or welded to the tube sheet where the tube protrudes from the surface. The tube sheet is usually a single round plate of metal that has been suitably drilled and grooved to take the tubes (in the desired pattern), the gaskets, the spacer rods, and the bolt circle where it is fastened to the shell. However, where mixing between the two fluids (in the event of leaks where the tube is sealed into the tube sheet) must be avoided.

\subsubsection{SHELL AND SHELL-SIDE NOZZLES:}

The shell is simply the container for the shell-side fluid, and the nozzles are the inlet and exit ports. The shell normally has a circular cross section and is commonly made by rolling a metal plate of the appropriate dimensions into a cylinder and welding the longitudinal joint ("rolled shells"). Small diameter shells (up to around 24 inches in diameter) can be made by cutting pipe of the desired diameter to the correct length ("pipe shells"). The roundness of the shell is important in fixing the maximum diameter of the baffles that can be insert and therefore the effect of shell-to-baffle leakage. Pipe shells are more nearly round than rolled shells unless particular care is taken in rolling, In order to minimize out-of-roundness, small shells are occasionally expanded over a mandrel; in extreme cases, the shell is cast and then bored out on a boring mill.

\subsubsection{TUBE-SIDE CHANNELS AND NOZZLES:}

Tube-side channels and nozzles simply control the flow of the tube-side fluid into and out of the tubes of the exchanger. Since the tube-side fluid is generally the more corrosive, these channels and nozzles will often be made out of alloy materials (compatible with the tubes and tube sheets, of course). They may be clad instead of solid alloy.

\subsubsection{CHANNEL COVERS:}

The channel covers are round plates that bolt to the channel flanges and can be removed for tube inspection without disturbing the tube-side piping. In smaller heat exchangers, bonnets with flanged nozzles or threaded connections for the tube-side piping are often used instead of channels and channel covers.

\subsubsection{PASS DIVIDER:}

A pass divider is needed in one channel or bonnet for an exchanger having two tube-side passes, and they are needed in both channels or bonnets for an exchanger having more than two passes. If the channels or bonnets are cast, the dividers are integrally cast and then faced to give asmooth bearing surface on the gasket between the divider and the tube sheet. If the channels are rolled from plate or built up from pipe, the dividers are welded in place. The arrangement of the dividers in multiple-pass exchangers is somewhat arbitrary, the usual intent being to provide nearly the same number of tubes in each pass, to minimize the number of tubes lost from the tube count, to minimize the pressure difference across any one pass divider (to minimize leakage and therefore the violation of the MTD derivation), to provide adequate bearing surface for the gasket and to minimize fabrication complexity and cost. 


\subsubsection{BAFFLES:}

Baffles serve two functions: Most importantly, they support the tubes in the proper position during assembly and operation and prevent vibration of the tubes caused by flow-induced eddies, and secondly, they guide the shell-side flow back and forth across the tube field, increasing the velocity and the heat transfer coefficient.

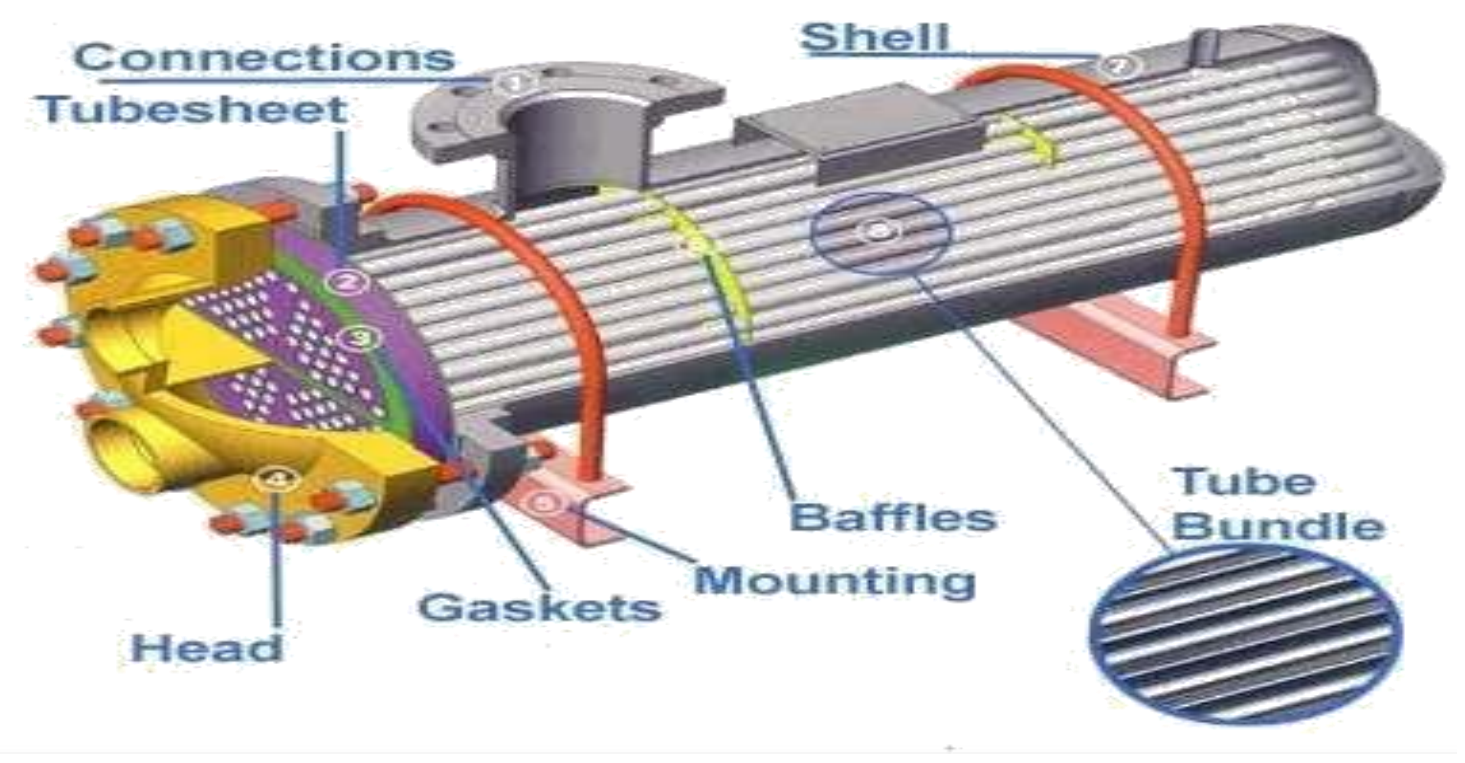

Fig.4-shell and tube heat exchanger

\section{DESIGN AND ANALYSIS}

The properties of the tube-side fluid at 20c,from Appendix B, are; $=4182$

$$
\begin{aligned}
\mathrm{K} & =0.598 \mathrm{~W} / \\
& =7.01 \\
& =998.2 \mathrm{~kg} / \mu=10.02 \times
\end{aligned}
$$

The properties of the shell-side fluid at average temperature,from the Appendix , are

$$
\begin{aligned}
& \mathrm{C} p=4179 \mathrm{~J} / \mathrm{kg} \cdot \mathrm{k} \\
& \mathrm{K}=0.612 \mathrm{~W} / \mathrm{m}^{2} . \mathrm{k} \\
& \operatorname{Pr}=5.75 \\
& p=995.9 \mathrm{~kg} / \mathrm{m}^{3} \\
& \mu=8.15 \times 10^{-4} \mathrm{~N} . \mathrm{s} / \mathrm{m}^{2}
\end{aligned}
$$

To solve the problem, first estimate the number of tube;

$$
\begin{aligned}
\mathrm{M}_{\mathrm{t}} & =p \mu_{\mathrm{m}} \mathrm{A}_{\mathrm{C}} \mathrm{N}_{\mathrm{t}} \\
\mathrm{N}_{\mathrm{t}} & =\mathrm{m} / \mathrm{p} \mu_{\mathrm{m}} \mathrm{A}_{\mathrm{C}} \\
& =4 \mathrm{~m}_{\mathrm{t}} / \mathrm{p} \pi \quad \mu_{\mathrm{m}} \\
& =4 \times 150 / 998.2 \times \pi \times(0.016)^{2} \times 2 \\
& =373.88 \\
\mathrm{~N}_{\mathrm{t}} & =374
\end{aligned}
$$


The flow area through the tube is

$$
\begin{aligned}
\mathrm{A}_{\mathrm{t}}=\pi \quad / 4 \times \mathrm{N}_{\mathrm{t}}= & \pi(0.016)^{2} / 4 \times 374 \\
& =0.075 \mathrm{~m}^{2}
\end{aligned}
$$

Now estimate the shell diameter from eq:

$$
=\left(\mathrm{N}_{\mathrm{t}}(\mathrm{CL})(\mathrm{PR})^{2} \quad\right) / 0.785(\mathrm{CTP})
$$

$\mathrm{CTP}=0.93$

$\mathrm{CL}=1.0$

$D_{s}=\left[374 \times 1 \times\left(2.54 \times 10^{-2} / 1.9 \times 10^{-2}\right)^{2}(0.019)^{2} / 0.785 \times 0.93\right]^{1 / 2}$

$=575 \mathrm{~mm}$

Which is rounded off as $580 \mathrm{~mm}$.

The selected and estimated constructional parameter can be summarized as

Shell inside diameter Ds $=058 \mathrm{~m}$

Number of tubes $\quad \mathrm{Nt}=1$

Tube outside diameter do $=19 \mathrm{~mm}$

Tube inside diameter

$$
\mathrm{d} 1=16 \mathrm{~mm}
$$

Square the pitch

$$
\mathrm{Pt}=0.0254 \mathrm{~m}
$$

Baffle spacing

$$
\mathrm{B}=0.5 \mathrm{~m}
$$

Kern Method Estimate the crossflow area at the shell diameter:

$\mathrm{A}_{\mathrm{S}}=\left(\mathrm{D}_{\mathrm{S}}-\mathrm{N}_{\mathrm{TC}} \mathrm{d}_{0}\right) \mathrm{B}$

Where, $\mathrm{N}_{\mathrm{TC}}=\mathrm{D}_{\mathrm{S}} / \mathrm{P}_{\mathrm{T}}$

$=580 / 25.4$

$=22.83$

$\mathrm{A}_{\mathrm{S}}=(0.58-22.83 \times 0.019) \times 0.5=0.073 \mathrm{~m}^{2}$

The equivalent diameter can be calculated from eqs.
$\mathrm{D}_{\mathrm{e}}=4($
/4)/ $\pi d_{0}$
$=4$
$=0.024 \mathrm{~m}$ 
Calculate the Raynolds number:

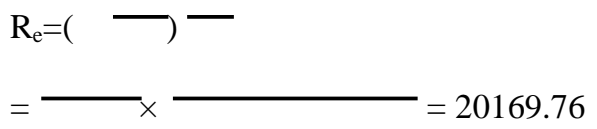

Assuming constant properties, the heat transfer coefficient can be estimated from eq,

$\mathrm{h}_{\mathrm{o}}=\mathrm{Re}^{0.55} \mathrm{pr}^{1 / 3}=$ $(20169.76)^{0.55}(5.57)^{1 / 3}=3793.6 \mathrm{~W} / \mathrm{m} 2 . \mathrm{K}$

Taborek Method: Consider the following.Taborek gives the following correlation for the shell-side heat

Transfer coefficient for turbulent flow;

$\mathrm{Nu}=0.2 \mathrm{Re}^{0.6} \operatorname{Pr}^{0.4}$

Where the Reynolds number is based on the tube outside diameter and the Velocity on the crossflow area at the diameter of the shell.

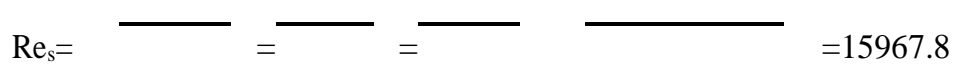

$\mathrm{Nu}=.2(15967.8)^{0.6}(5.57)^{0.4}=132.2$,

$\mathrm{h}_{\mathrm{s}}=\overline{=}=4259.09 \mathrm{w} / \mathrm{m}^{2} \cdot \mathrm{k}$

Bell-Delaware Method:The shell-side heat transfer coefficient is given by eq,

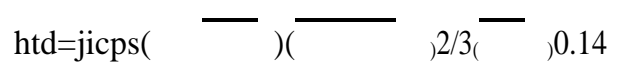

where, $\mathrm{j}_{\mathrm{i}}=0.37 \mathrm{Re}_{\mathrm{s}}^{-0.395}$

where

$$
\begin{aligned}
\operatorname{Re}_{\mathrm{s}}= & \longrightarrow=15967.8 \\
\mathrm{j}_{\mathrm{i}}=0.37 \mathrm{Re}_{\mathrm{s}}^{-0.395}=0.0081 & \\
& \mathrm{~h}_{\mathrm{u}}=0.0081 \quad 4179(\longrightarrow)(\longrightarrow)^{2 / 3} \\
\mathrm{~h}_{\mathrm{u}}= & 7382.8 \mathrm{~W} / \mathrm{m}^{2} \cdot \mathrm{k}
\end{aligned}
$$

It is assumed that the properties are constant. In the Bell-Delaware method the correction factors Due to bypass and leakage stream are provided in graphical forms depending on the constructional features of the heat exchanger. Let us assume that combined effect of all these correction factore is $60 \%$, 


$$
\mathrm{h}_{\mathrm{o}}=0.60 \quad \mathrm{~W} / \mathrm{m}^{2} . \mathrm{k}
$$

Therefore, the three above method have demonstrated comparable results to estimate the shell-side heat transfer coefficient.

Tube -side Heat Transfer Coeffient

$$
\operatorname{Re}_{\mathrm{i}}=\square=\bar{\square}=31878.6
$$

The tube-side heat transfer coefficient, can be calculated from the Petukhov-kirilov correlation

As given by eq;

$$
\begin{aligned}
& \mathrm{Nu}_{\mathrm{b}}= \\
& \mathrm{f}=\left(1.58 \ln \mathrm{Re}_{\mathrm{b}}-3.28\right)^{-2}=\left[1.58 \mathrm{in}(31878.6-3.28]^{-2}=.0058\right. \\
& \mathrm{f} / 2=0.0029 \\
& \quad \mathrm{Nub}=\frac{-}{\mathrm{h}_{\mathrm{t}}=(224.16) \_}=83 \overline{-}-\overline{\mathrm{w}} / \mathrm{m}^{2} \cdot \mathrm{k}
\end{aligned}
$$

The overall heat transfer coefficient for the clean suface is

$$
\begin{aligned}
& =+\mp- \\
& \begin{array}{c}
=\longrightarrow+\frac{+}{+1}+\frac{}{2}+\mathrm{W} / \mathrm{m}^{2} \cdot \mathrm{k}
\end{array}
\end{aligned}
$$

And for the fouled surface is

$$
\begin{aligned}
& 1709.7 \mathrm{~W} / \mathrm{m}^{2} . \mathrm{k} \\
& \mathrm{T}_{\mathrm{C} 2}=-+\mathrm{T}_{\mathrm{c} 1} \\
& \mathrm{~T}_{\mathrm{C} 2}=\longrightarrow+20=22.33 \mathrm{C} \\
& \mathrm{LMTD}=\longrightarrow=7.09 \mathrm{c} \\
& \mathrm{Q}=(\mathrm{m} \quad) \mathrm{h}\left(\mathrm{Th}_{1}-\mathrm{Th}_{2}\right)=50 \times 4179 \times(32-25) \\
& \mathrm{Q}=\mu_{\mathrm{f}} \mathrm{A}_{\mathrm{f}} \Delta \mathrm{T}_{\mathrm{m}} \\
& \mathrm{Af}_{\mathrm{f}}==120.66 \mathrm{~m}^{2} \\
& \mathrm{~A}_{\mathrm{c}}=\longrightarrow=84.36 \mathrm{~m}^{2}
\end{aligned}
$$

The over surface desine is

$$
\mathrm{OS}=-=-=-=1.43
$$


Which is the clean fouling safety factor. The over surface desine shouid not be more than about $30 \%$ Assuming $20 \%$ surface over desine, the cleaning scheduling must be arranged accordingly.

$$
\begin{aligned}
& -=1.20 \\
& \mu_{\mathrm{f}}=\square=\square=2037.9 \mathrm{~W} / \mathrm{m}^{2} . \mathrm{k}
\end{aligned}
$$

The corresponding total resistance can be calculated

$$
\mathrm{R}_{\mathrm{ft}}=0.0000817 \mathrm{~m}^{2} . \mathrm{k} / \mathrm{w}
$$

For $20 \%$ over surface desine, the surface area of the exchange becomes

$$
\begin{aligned}
& A_{f}=1.20 A_{C} \\
& A_{f}=1.20 \times 84.36=101.2 \mathrm{~m}^{2}
\end{aligned}
$$

The length of the heat exchanger is calculated as follows:

$$
\mathrm{L}=\widetilde{T}=4.54 \mathrm{~m}
$$

Which is rounded off to $\mathrm{L}=5 \mathrm{~m}$

The shell diameter can be recalculated from eq;

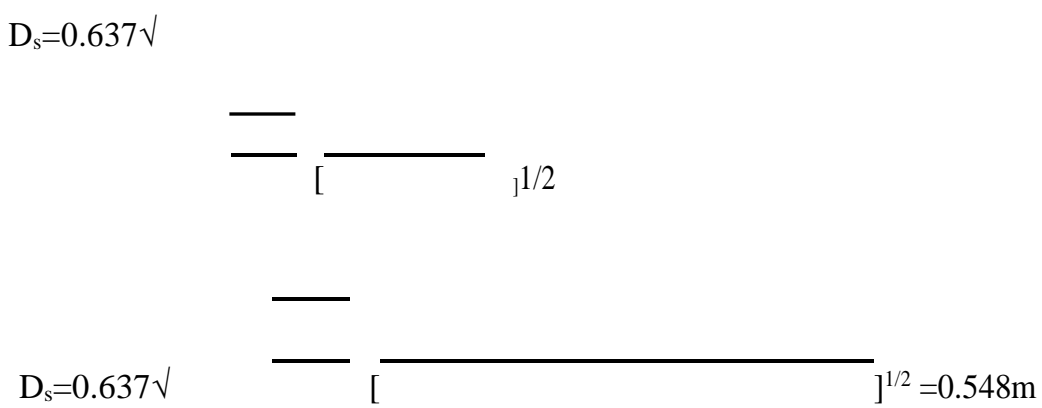

Which is rounded off to $D=60 \mathrm{~m}$.

Now we have to rate the heat exchanger using the Bell-Delaware method and assuming 
$\mathrm{D}_{\mathrm{S}}=0.58 \mathrm{~m}, \mathrm{~N}_{\mathrm{t}}=374, \mathrm{~L}=5 \mathrm{~m}, \mathrm{~d}_{\mathrm{o}}=19 \mathrm{~mm}, \mathrm{~d}_{\mathrm{i}}=16 \mathrm{~m}, \mathrm{~B}=0.50 \mathrm{~m}, 25 \%$ baffle cut $, \mathrm{P}_{\mathrm{T}}=0.0254 \mathrm{~m}, \mathrm{~L}_{\mathrm{c}}=.25 \mathrm{D}_{\mathrm{S}}$

Total pressure drop over the shell side of the heat exchanger is $\Delta \mathrm{p}_{\mathrm{s}}=\Delta \mathrm{p}_{\mathrm{c}}+\Delta \mathrm{p}_{\mathrm{w}}+\Delta \mathrm{p}_{\mathrm{e}}$

$\Delta \mathrm{p}_{\mathrm{s}}=\left[\left(\mathrm{N}_{\mathrm{b}}-1\right) \Delta \mathrm{p}_{\mathrm{b}} \mathrm{R}_{\mathrm{b}}+\mathrm{N}_{\mathrm{b}} \Delta \mathrm{p}_{\mathrm{w}}\right] \mathrm{R}_{\mathrm{i}}+2 \Delta \mathrm{p}_{\mathrm{b}}(1+\quad \rightarrow) \mathrm{R}_{\mathrm{s}} \mathrm{R}_{\mathrm{b}}$

The pressure drop in the nozzle must be calculated separately and added to the total pressure drop.

In eq. $\Delta \mathrm{p}_{\mathrm{bi}}$ is calculated from

$$
\Delta \mathrm{p}_{\mathrm{bi}}=4 \mathrm{f}_{\mathrm{t}} \quad-(-)^{0.14}
$$

the tubes are laid out in square pitch

, and the area of the baffle windows, $\mathrm{A}_{\mathrm{w}}=0.076 \mathrm{~m}^{2}$.

The estimate crossflow area at the shell diameter

$$
\mathrm{A}_{\mathrm{s}}=0.073 \mathrm{~m}^{2}
$$

The number of the rows crossed in one crossflow section , $\mathrm{N}_{\mathrm{ct}}$ can be cakculate.

$$
-=0.25
$$

From table ,

$$
\begin{gathered}
\mathrm{P}_{\mathrm{p}}=1 \ln =0.0254 \mathrm{~m} \\
\mathrm{~N}_{\mathrm{c}}=\square \\
\mathrm{N}_{\mathrm{c}}=0.58 \quad-10.0254=12
\end{gathered}
$$

The Reynolds number is based on the tube outside diameter and the velocity on the crossflow area at the diameter of shell.

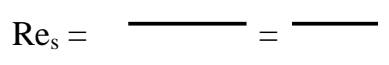

Which was calculated

$$
\operatorname{Re}_{\mathrm{s}}=15968
$$


Now, calculated the friction coefficient, which is given by eq;

$$
\mathrm{f}_{\mathrm{t}}=\mathrm{b}_{1}(\longrightarrow)^{\mathrm{b}}\left(\operatorname{Re}_{\mathrm{s}}\right)^{\mathrm{b}_{2}}
$$

Since $\mathrm{P}_{\mathrm{T}} / \mathrm{d}_{\mathrm{o}}=1.33$, this eq. can be simplified to

$$
\mathrm{f}_{\mathrm{t}}=\mathrm{b}_{1}\left(\operatorname{Re}_{\mathrm{s}}\right)_{2}{ }_{2}
$$

From table $b_{1}=0.391, b_{2}=-0.148$, there for the friction coefficient

$$
\mathrm{f}_{\mathrm{t}}=0.391(1568)^{-0.148}=0.093
$$

If there were no leakage or bypass the pressure drop in one crossflow section can be calculated from eq:

$$
\begin{aligned}
& \Delta \mathrm{p}_{\mathrm{bi}}=4 \mathrm{f}_{\mathrm{t}} \quad-\left({ }^{\prime} 0.14_{\mathrm{Nc}}\right. \\
& \mathrm{G}_{\mathrm{s}}=\square=\overline{=}=684.9 \mathrm{~kg} / \mathrm{m}^{2} \mathrm{~s} \\
& \Delta \mathrm{p}_{\mathrm{bi}}=4 \\
& =1055 \mathrm{~Pa}
\end{aligned}
$$

Assuming $\mathrm{R}_{\mathrm{b}}=0.60$ and $\mathrm{R}_{\mathrm{LC}}=0.4 \mathrm{THE}$ combined pressure drop of the entire interior crossflow section can be calculated from eq;

$$
\begin{array}{ll}
\mathrm{p}_{\mathrm{c}}=\mathrm{p}_{\mathrm{bi}}\left(\mathrm{N}_{\mathrm{b}}-1\right) \mathrm{R}_{\mathrm{L} . \mathrm{C}} \mathrm{R}_{\mathrm{b}} & \\
\mathrm{p}_{\mathrm{c}}=1137(9-1) .60 & =2.18 \mathrm{kPa}
\end{array}
$$

Where $\mathrm{N}_{\mathrm{b}}$ is the number of baffle,

$$
\mathrm{N}_{\mathrm{b}}=-1
$$

Where $\mathrm{P}_{\mathrm{P}}$ IS given in table as $0.0254 \mathrm{~m} . \mathrm{L}_{\mathrm{C}}$ is the baffle cut distance from the baffle tip to the shell inside diameter:

$$
\begin{aligned}
& \mathrm{L}_{\mathrm{c}}=.25 \mathrm{D}_{\mathrm{S}}=0.25 \quad 0.580=0.145 \mathrm{~m} \\
& \mathrm{Ncw}=
\end{aligned}
$$

The area of flow through the baffle windows is 


$$
A_{w}=A_{w g}-A_{w l}
$$

Where $A_{w g}$ is the gross windows area and $A_{w l}$ is the windows area occupied by tubes.

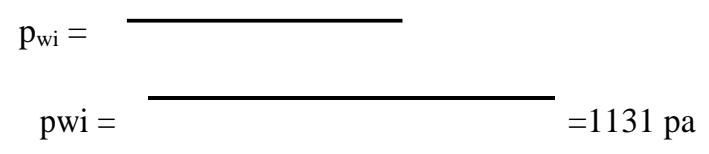

Given as $\mathrm{A}_{\mathrm{w}}=0.076 \mathrm{~m}^{2}$

The total pressure drop in all windows is

$\Delta \mathrm{Pw}=\Delta \mathrm{PWINbRl.c.}$

$$
\Delta \mathrm{P}_{\mathrm{w}}=1131 \times 9 \times 0.4=4072 \mathrm{~Pa}
$$

The total pressre drop over the heat exchanger on shell side can be calculated fro eq:

$$
\mathrm{p}_{\mathrm{s}}=\left[\begin{array}{llll}
( & \mathrm{b}-1) & \mathrm{p}_{\mathrm{bi}} \mathrm{R}_{\mathrm{b}}+\mathrm{N}_{\mathrm{b}} & \mathrm{p}_{\mathrm{wi}}
\end{array}\right] \mathrm{R}_{\mathrm{L} . \mathrm{C} .}+2 \mathrm{p}_{\mathrm{bi}}(1+\quad \longrightarrow) \mathrm{R}_{\mathrm{b}} \mathrm{R}_{\mathrm{s}}
$$

Baffle spacings in the inlet, exit, and central reglons are equal, so $R_{s}=1$.

$$
\mathrm{p}_{\mathrm{s}}=[(9-1) \quad 1105 \quad 0.60+9 \quad 1131] 0.4+2 \quad 1105 \quad(1+\longrightarrow) \quad 0.60=8.07 \mathrm{kpa}
$$

Which is less than the allowable pressure drop, so the heat exchanger is suitable. The shell-side pressure drop couid be overestimated if it were calculated without

Baffle leakage and without baffle leakage and without tube bundle bypass effects.

Now calculate the shell-side pressure drop,

$$
\mathrm{p}_{\mathrm{s}}=
$$

Where $D_{r}$ is the equivalent diameter, which is calculate from eqn.

$$
\mathrm{D}_{\mathrm{r}}=0.024 \mathrm{~m}
$$

The friction coefficient is calculated from eqn.

$$
\operatorname{Re}_{\mathrm{s}}=(\longrightarrow)-\mathrm{G}_{\mathrm{s}}
$$

Where, $\operatorname{Re}=20170$

Then,

$$
\mathrm{f}=\exp \left(0.576-0.19 \ln \operatorname{Re}_{\mathrm{s}}\right)
$$

$$
\mathrm{f}=0.271
$$

Assuming that $\quad s=1$ and inserting the calculated value into eqn. so,

$$
\mathrm{p}_{\mathrm{s}}=\overline{=}=0.271\left(\overline{{ }^{2}}=15400 \mathrm{~Pa}=15.4 \mathrm{~Pa}\right.
$$

The shell-side pressure drop obtained by Bell-Delaware method is about $48 \%$ lower than that obtained by the kern method. 


\section{DESIGN FIGURE}

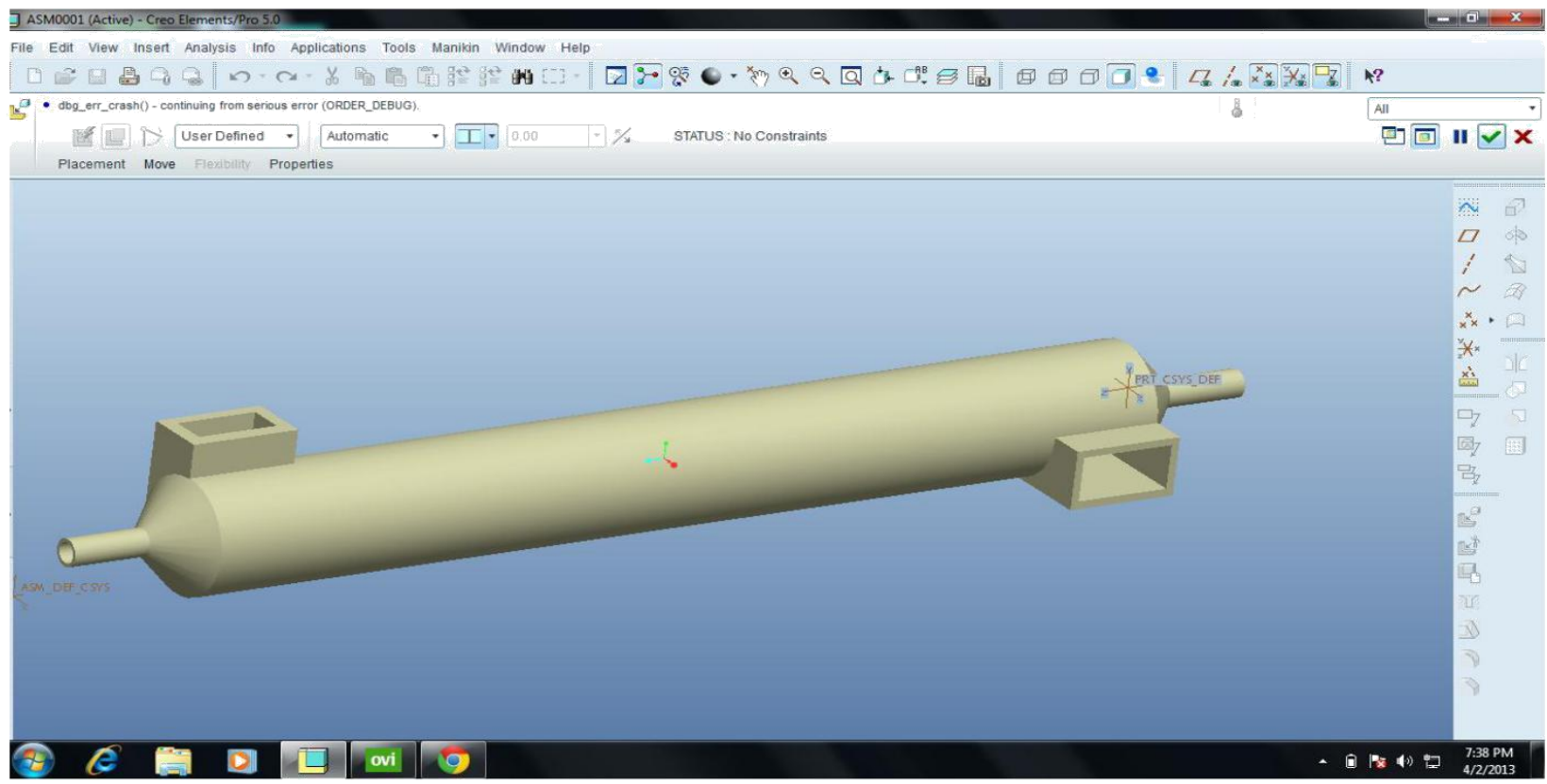

1 PRT0001 (Active) - Creo Elements/Pro

File Edif View Insent Analysis Info Applications Tools Window Help

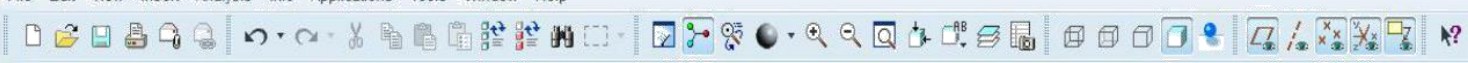

- dbg_err_crashí - continuing from serious error (ORDER_DEBUG).

(B) कि

$$
\text { Model Tree }
$$

TPRTO001 PRT

पRIGT

$\triangle$ TOP

* PRT_CSYSDEF

* E EitiudeI

+ Dititude:

+9 Eitrude 3

- Teitrude 4

7- 9 Pattem 1 of Extrude's

+ Gattem 2 of Extrude 6 .

+ 1 Pattem 3 iof Eitrude 7

+ - Pattein 4 of Extrude 8

+ JPattern 5of Extrudel

- Battem 6 of Extrude 10

G Pattern 7 of Extrude11

+ 9 Pattem 8 of Extrude 12

+ - Pattern 9 of Extride:

- - Pattern 10 of Eitrude 14

Fian Pattem 11 of Extrude 15

-8 Protrusion id 33233

- Protiusion id 3322

+ De Extude16.

+ G Extrudelt

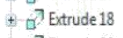

$1+0$ Eitude 20

+ D? Eitrude 21.

07 Eitrude 22

+ 5itiude 23

5itride 24.

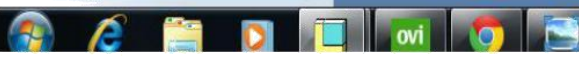

8

Smart
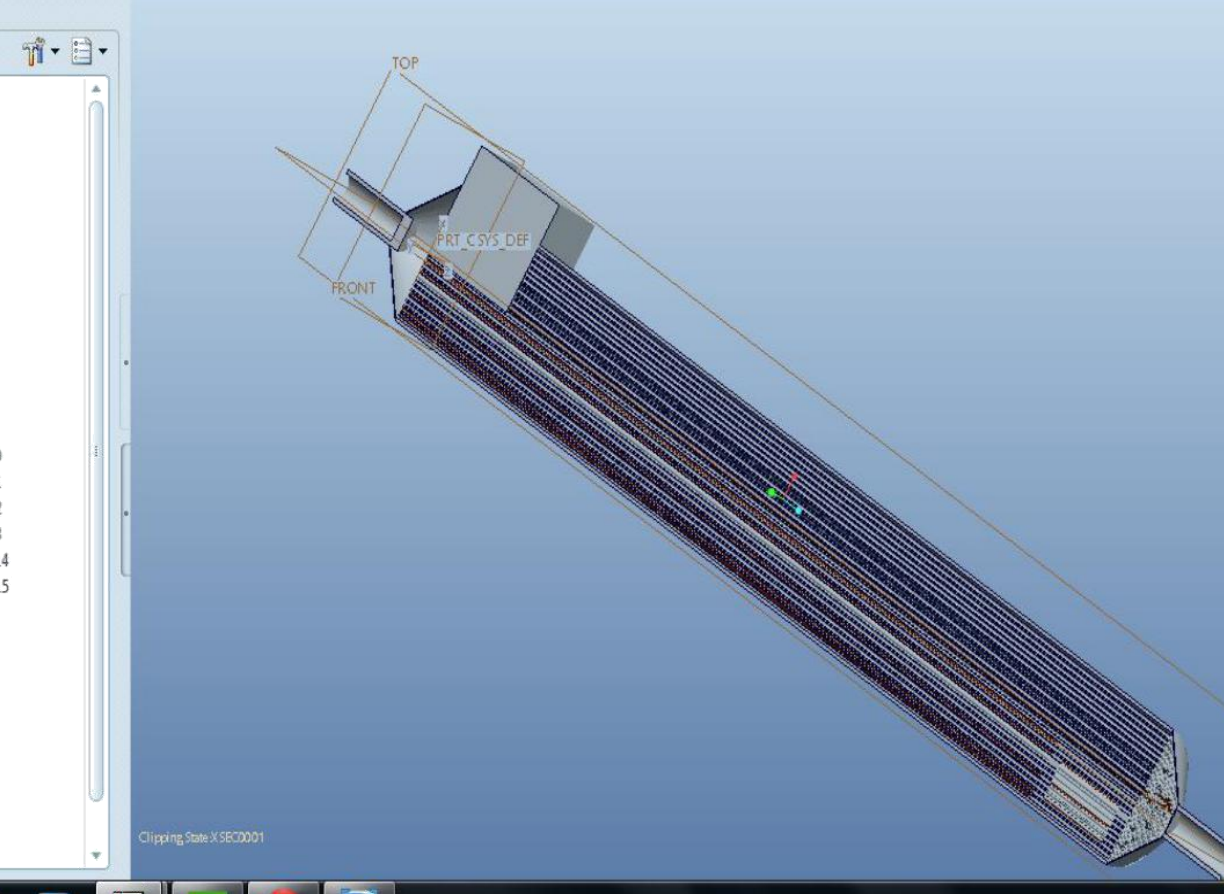


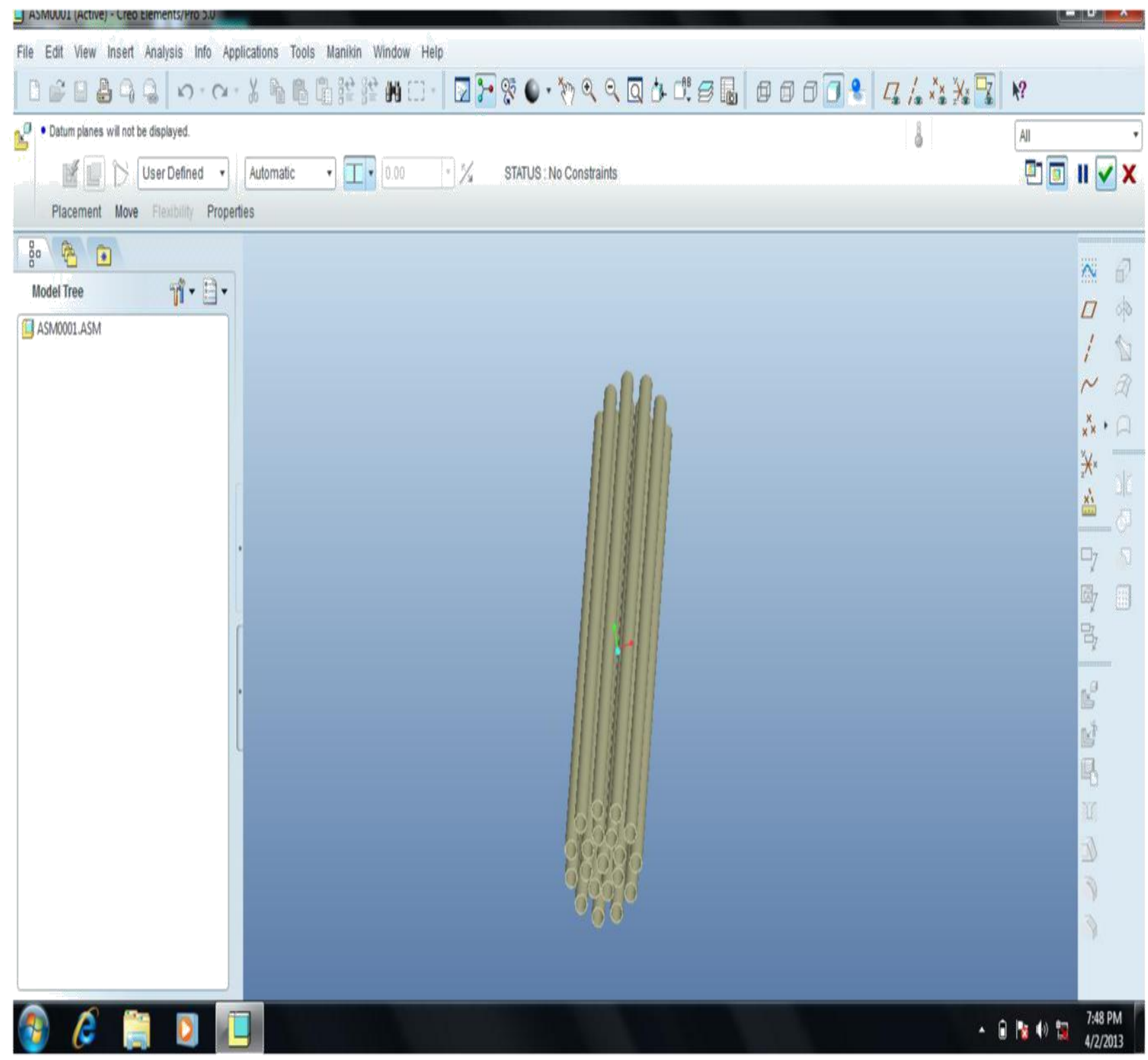




\section{ADVANTAGE OF SHELL AND TUBE HEAT EXCHANGER}

The Design of Shell and Tube Heat Exchangers is very compact.

It capable to handling with High Pressure.

It less expensive too.

Can be used in systems with higher operating temperatures and pressures

Pressure drop across a tube cooler is less

Tubular coolers in refrigeration system can act as receiver also.

Using sacrificial anodes protects the whole cooling system against corrosion

Due to the pressure differential use coolers may be preferred for lubricating oil cooling.

\section{DISADVANTAGE OF SHELL AND TUBE HEAT EXCHANGER}

It is very tough to readily analyze the shell side of the tubes for scaling or tube damage Less efficiency in Heat Exchanger

Cleaning and maintenance is Problematic since a tube cooler requires enough clearance at one end to remove the tube nest

It cannot be increased the capacity of tube cooler.

It requires more space for drop it at one place.

\section{EXCEPTED OUTCOME}

Our main objective is to Design the Shell and Tube Heat Exchanger in this way, which gives maximum heat transfer between both the fluids.

$\square \quad$ Optimize the design, which reduces the cost of shell and tube heat exchanger.

\section{REFERENCES}

http://chemicalengineeringnow.com/HeatExchanger.aspx

www.engineersedge.com

http://www.calculatoredge.com

http://heattransfer.asmedigitalcollection.asme.org/journal.aspx

https://www.tandfonline.com/doi/full/10.1080/01457632.2018.1457241

https://www.sciencedirect.com/science/article/pii/S187770581502799X

https://www.scimagojr.com/journalsearch.php?q=16112\&tip=sid

https://www.begellhouse.com/journals/enhanced-heat-transfer.html

https://www.begellhouse.com/journals/heat-exchanger-design-updates.html

https://www.researchgate.net/journal/1524-5608_International_Journal_of_Heat_Exchangers

https://www.journals.elsevier.com/international-journal-of-heat-and-mass-transfer

https://www.emeraldinsight.com/doi/abs/10.1108/09615531011048240

https://www.ijsr.net/?gclid=Cj0KCQjwpPHoBRC3ARIsALfx-

_I_0D5GwbL5QOWkpMysvqgu2zIJ5ungIzerDCCFtbF_Qqbt5C0qQ8aAobeEALw_wcB

http://gma-tech.com/en/?gclid=Cj0KCQjwpPHoBRC3ARIsALfx-

_I7bwUQikvYcTPtVIED8KjZZrFMuXfvr410UpyIUwEtbzy9fAAqIA4aAtxJEALw_wcB

https://www.irjet.net/archives/V5/i1/IRJET-V5I1308.pdf

https://www.academia.edu/30973704/REVIEW_OF_HEAT_EXCHANGERS

https://onlinelibrary.wiley.com/journal/15231496

http://stmjournals.com/tech/index.php?journal=JoTEA\&page=article\&op=view\&path\%5B \%5D=154

https://aip.scitation.org/doi/10.1063/1.4991014

https://arc.aiaa.org/loi/jtht

https://www.worldscientific.com/doi/abs/10.1142/S2010132511000624

https://www.sciencepubco.com/index.php/ijet/article/view/23834

Fundamental of heat and mass transfer by C.P kothandaraman

Introduction to investment casting by M/s. Laxminarayan .

Heat and mass transfer by R.K RAJPUT.

Heat and mass transfer by Dr. D.S Kumar.

An Introduction to Computational Fluid Dynamics Chapter 20 in Fluid Flow Handbook By Nasser Ashgriz \& Javad Mostaghimi Department of Mechanical \& Industrial Eng.University of Toronto Toronto, Ontario.

Introduction to CFD Basics by Rajesh Bhaskaran Lance Collins.

Design of experiment using the taguchi approach by Ranjit K Roy

Heat Exchangers: Selection, Rating, and Thermal Design By Sadik Kakac, Anchasa Pramuanjaroenkij, Hongtan Liu

Heat and Mass Transfer by D.S.Kumar 